\title{
Impact of Total Quality Management (TQM) on Operational Performance of Ethiopian Pharmaceutical Manufacturing Plants
}

\author{
Dr. Seid Mohammed ${ }^{1}$, Dr. Goulap Jagadish Brahma ${ }^{2}$ and Shegaw Aderaw ${ }^{3}$ \\ ${ }^{1}$ Manager, Commissioned Education Program, Assistant Professor, Department of Management, College of Business and \\ Economics, Addis Ababa University, ETHIOPIA \\ ${ }^{2}$ Associate Professor, Department of Management, College of Business and Economics, Addis Ababa University, ETHIOPIA \\ ${ }^{3}$ Factory Director, Sino Ethio, ETHIOPIA \\ ${ }^{2}$ Corresponding Author: jagadishbrahma@gmail.com
}

\begin{abstract}
S
The purpose of this study is to examine the impact of TQM system on the operational performance of the pharmaceutical manufacturing companies operating in Ethiopia. Data for this study is collected using selfadministered questionnaires. The survey is carried out on 65 respondents drawn from 13 companies. Out of 65 questionnaires distributed among these companies, a total of 57 got returned. Through comprehensive literature review, seven critical success factors of TQM that are relevant to the pharmaceutical industry are identified. Correlation \& regression analyses are used to investigate the relationship between TQM variables on the one side and common operational performance measures (Quality, Cost, and Delivery \& Flexibility to volume) on the other side. The Correlation analysis reveals that there is strong relationship between TQM practices and operational performance among the pharmaceutical manufacturing companies. The outcome of regression analysis indicates that customer focus, process management, product design and people management have significant contribution to at least one of the operational performance measures. Top Management's support, suppliers' quality management and continuous improvement do not appear to contribute to higher levels of performance. This study offers pharmaceutical companies and their managers a better understanding of the relationship and impact that some of TQM elements have on the performance of their operations. Thus managers will get an opportunity to take better \& more effective decisions in the implementation of TQM. This study can also guide organizations to prioritize the implementation of TQM based on the strategic importance of performance measures needed by them. The choice performance measure is based on the perceptions of managers and therefore, generalization of the observations may be made with caution.
\end{abstract}

Keywords-- Total Quality Management, Operational Performance, Pharmaceutical Manufacturing Companies, Ethiopia

\section{INTRODUCTION}

Manufacturing industries need to improve the quality of their products and services so as to remain competitive and cope with increasing business challenges. To meet the challenge of global competition, many businesses have invested substantial resources in adopting and implementing Total Quality Management (TQM) strategies (Demirbag, Tatoglu, Tekinkus and Zaim2006). The challenge is even tougher for the manufacturing firms among least developed countries such as Ethiopia, where the industry is at infant stage and is faced with stiff competition from imported products front(WTO 2017).

The pharmaceutical industry is a vital segment of health care system, which is regulated heavily because, any mistake in product design or in the production process can result in severe, or even deadly, consequences for patients, a situation that sometimes leads to recall of the drug from the market. Hence, quality and its management are very critical in this industry (Kumar, Jasbir, Davinder and Mamta 2016).

The Ethiopian pharmaceutical industry has been identified as one of the eight priority subsectors for the Medium and Large Industries Development in the Growth and Transformation Plan (MOFED, 2010). A viable pharmaceutical industry in Africa is not only making an impact on the country's health system and its capacity to respond to the health needs of the people but is also contributing to the overall socio-economic development of the continent (AU,UNIDO,2012).

A study by United Nation Conference in Trade and Development (UNCTAD, 2011) shows that producing pharmaceuticals locally is important as it will improve the country's economy through import substitution, increases employment opportunities and improve shelf life of the products by decreasing the long lead time incidental with importation.

TQM is a strategic management tool that can be used for improving the competitiveness, effectiveness and flexibility of the whole organization (Oakland, 2003 p. 30). Total quality management plays a major role in stages right from initial establishment of the firm, safeguarding marketed products and controlling the overall quality- 
system chain (Patel andMaheswari, 2016).Raja, Bodla and Malik (2011) argues that there is a growing recognition with in the manufacturing sector that a holistic strategy is needed to bring competitive advantage in the market place and this can only be achieved through adopting TQM system.

The Ethiopian pharmaceutical Industry is characterized by lowest level of industrialization and poor performance, poor production capacity, poor innovativeness, poor product quality and poor exporting capacity (WTO 2017). As a result, the Ethiopian pharmaceutical industry's contribution to the country's GDP is very low. (MOI and MOH, 2015).

According to World Health Organization (WHO, 2011), most of the pharmaceutical industry in the least developed countries work under constraints such as high operating costs and low production quality standards. The annual pharmaceutical market in Ethiopia is estimated to be worth US\$ 400 to US\$ 500 million and growing at an impressive rate of $25 \%$ per annum (MOH, MOI, 2015). In 2014, the Ethiopian industry exported pharmaceutical products worth almost US\$ 2 million, which was far below the GTP-I target of US\$ 20 million (MOI and MOH, 2015). Estimates on the share of the market held by local producers of pharmaceuticals vary between 15 and 30 percent (UNCTAD, 2011).

Despite the growing need for pharmaceuticals, local pharmaceutical firms in Ethiopia are not utilizing their full capacity and they are facing fierce competition from imported products. Current manufacturing suffers from operational inefficiencies (MOH, MOI, 2015).

Ethiopian manufacturing organizations are expected to improve their product quality in order to enhance their competitiveness in global market. Ethiopia is in the phase of accession to the World Trade Organization (WTO). Becoming a member of WTO requires the country to open up most of the sectors of the economy to the global economy and the local companies need to prepare a head for fierce competition from foreign companies (Haile and Raju, 2016).

Though there is no much information about the current status of TQM implementation of the pharmaceutical industry in Ethiopia, it is expected that the local manufacturers are implementing TQM practices to achieve their organizational goals.

The pharmaceutical production requires a strong quality focus, efficient production \& best customer services, which cannot be achieved without adopting effective manufacturing practices such as TQM that impact on operational performance. Accordingly it is necessary to assess the nature of the current practices of TQM implementation and to examine the impact of TQM practices on the performance of the pharmaceutical manufacturing companies.
This research proposal is, therefore, designed to study the relationship of the implementation of TQM and its impact on performance of pharmaceutical manufacturing firms in Ethiopia.

\section{BRIEF RESEARCH REVIEW}

Various scholars and quality gurus have proposed different principles and practices about Total Quality Management. Martínez-Lorente, Dewhurst, Dale and Barrie (1998), mentioned that Crosby, Deming, Feigenbaum, Ishikawa and Juran can be considered as the most important gurus of the quality management movement. While each has his/her own understanding and explanation of quality management concept, there are common points which they share such as the importance of top management's commitment, focusing on customer satisfaction; emphasis on prevention of product defects; continuous improvement and employee empowerment.

The identification of key factors of TQM helps the companies to better understand the concepts of TQM and for its successful implementation on respective companies.

Flynn, Sakakibara and Schroeder (1995) developed the quality management framework for manufacturing firms, including top management support, workforce management, quality information, supplier involvement, product design, process management, and customer involvement.

According to Cua, Mc.Kone, and Schroeder (2001), there are nine practices that are commonly cited as part of a TQM program. These practices are crossfunctional product design, process management, supplier quality management, customer involvement, information and feedback, committed leadership, strategic planning, cross-functional training, and employee involvement.

Kumar et al., (2016) in their study of recognizing the importance of TQM practices in Indian pharmaceutical industry have emphasized that there are six factors affecting the implementation of TQM. These are: Top Management's Commitment, Leadership, Quality Management, People Management and Training, Customer Focus and Supplier Quality.

Demirbag et al., (2006) conducted an empirical study to identify factors critical to the success of TQM in the Turkish small \& medium size enterprises. They concluded that there are seven CSFs of TQM practices, i.e., quality data and reporting, role of top management, employee relations, supplier quality management, training, and quality policy and process management.

In another study, Anderson, Rungtusanatham and Schroeder (1994), identified seven factors using Delphi method. These are visionary leadership, internal and external cooperation, learning, process management, 
continuous improvement, employee fulfillment, and customer satisfaction.

Haile and Raju (2016), while examining the extent of TQM implementation by Ethiopian manufacturing firms, indicated that most recognized success factors of TQM in literature are: Top Management Leadership and Commitment, Customer Focus, Supplier Quality Management, People Management, Process Management, and Continuous Improvement.

After exhaustive literature reviews, the researchers identified seven critical success factors for this study. To select these factors the researchers considered the importance and relevance of these factors to the manufacturing industry in general and the pharmaceutical industry in particular. More over the researchers considered the frequency of TQM factors as they appear in the various related researches.

Accordingly the following critical success factors were used in this study: Top Management Support, Supplier Quality Management, Customer Focus, People Management, Process flow management, Product Design and Continuous Improvement.

Many researchers have indicated that there is strong positive relationship between TQM practices and organizational performance. For example, Samson and Terziovski (1999), as cited in the study of Munizu (2011), investigated the effect of TQM practices on organizational performance of manufacturing companies in Australia and New Zealand. They found that there is strong relationship between TQM practice \& organizational performance but not in all categories of TQM. The categories of leadership, management of people and customer focus were the strongest significant predictors of operational performance.

Salaheldin (2009) surveyed Small and Medium Enterprises (SMEs) in Qatar to investigate relationship between TQM and performance of the firms. The findings confirm the existence of significant relationship between TQM and organizational performance among SMEs.

Lakhal (2009) studied the impact of quality improvement on competitive advantage and organizational performance of companies in Tunisia and found out that quality improvement can lead to enhanced competitive advantage and improved organizational performance.

Hassan, Mukhtar, Ullah and Sidra (2012), in their study of the impact of TQM on manufacturing firms in Pakistan reported that successful adoption and implementation of TQM practices results in improving the performance of organization. The main implication of the findings for managers is that with TQM practice, manufacturing organizations are more likely to achieve better performance in customer satisfaction, employee relations, quality and business performance than without TQM practices.

On the other hand, Powell (1995), while investigating the impact of TQM on competitive advantage of US companies, suggested that most features generally associated with TQM such as quality training, process improvement, and benchmarking do not generally produce advantage, but that certain features such as open culture, employee empowerment, and executive commitment can produce advantage.

In general, operational performance is defined as the extent to which an operation meets performance goals, the major steps in order to meet customer needs (Slack, Brandon and Johnston, 2013).

Operational performance deals with the process and evaluates the performance of internal operation of the company in term of cost, customer services, delivery, quality, flexibility, and product-/service-process quality (Brah and Lim, 2006).

Review of the above empirical studies indicates that there is positive relationship between proper implementation of TQM practices and operational performance of an organization.

The operational performance measures which are considered in this study are cost performance, quality performance, delivery performance, and flexibility to volume performance. These variables are considered to be dependent variables.

Operational performance is measured by the quality, delivery, flexibility and cost scales as developed by Boyer and Pagell (2000), Flynn et al. (2014) andCua et al. (2001) that assessed opinion of managers on the level of operational performance. According to these researchers, quality performance is measured with conformance to product specifications, performance and consentient and reliable product quality. Delivery performance is measured along providing fast deliveries, meeting delivery promises and reducing production lead time. Flexibility to volume performance is measured by making rapid design changes, adjusting capacity quickly, making rapid volume changes, and adjusting product mix quickly. Cost performance is measured through reduction in inventory, increase in capacity utilization, reduction in production costs and increase in labor productivity.

Based on the above research review, the following conceptual Model is proposed: 
Independent Variables

\begin{tabular}{|l|l|l|}
\hline TQM Practices & \multicolumn{2}{|c|}{ Dependent variables } \\
\hline Top Management Support & & Operational Performance \\
Customer Focus & & Quality \\
People Management & Delivery \\
Process Management & Cost \\
Continuous Improvement & & Flexibility \\
Product Design & \\
Supplier Quality Management & \\
&
\end{tabular}

Figure 1: Conceptual Frame Work

Based on theoretical and practical evidences, the following hypotheses are proposed:

Proposition:

TQM Practices are positively associated with the level of operational performance. It is expected that the relationship of TQM practices with operational performance is positive. The above proposition can be validated through empirical tests of following hypotheses:

Hypothesis $\mathrm{H}_{1}$ :

TQM Success factors are positively associated with Cost Performance

Hypothesis $\mathbf{H}_{2}$ :

TQM Success factors are positively associated with Quality Performance

Hypothesis $\mathrm{H}_{3}$

TQM Success factors are positively associated with improved Delivery Performance

Hypothesis $\mathrm{H}_{4}$

TQM Success factors are positively associated with Flexibility to Volume performance.

\section{RESEARCH METHODOLOGY}

The purpose of this study is to examine the relationship of TQM practices and operational performance of the Ethiopian pharmaceutical manufacturing firms. Besides, exploratory research is suitable for this study as it aims at identifying causal relationships between and among variables.This study is conducted using quantitative research approach since it is an appropriate method to create quantifiable cause and effect relationship between and among the variables of the study.

The unit of reference is every pharmaceutical manufacturing company existing in Ethiopia that is engaged in manufacturing of medicines. There are 13 pharmaceutical companies in Ethiopia that produce medicinal products according to the Ministry of Industry. Since all the companies are considered for the study, it becomes a Census study. The respondents among all these companies are managers who are working in quality control, quality assurance, production, research \& development, technical plant managers and other quality experts summing up to 65 .

The study is based on both primary and secondary data. The primary data are collected directly from the respondents through self-administered questionnaire. The targeted respondents are managers of each respective company who are assumed to have the required knowledge of the study \& provide the most relevant information about the company concerned.

The information resulting from the primary data is sought to be more consistent with the research questions and objectives.The decision to use questionnaire is taken with the object of broaden the respondent base.

\section{Design of the Questionnaire}

The Survey instrument (questionnaire) is adapted to those used in similar studies of Sila and Ebrahimpour (2005), Phanand Matsui (2006), SadikogluandOclay (2014), Powell (1995), Cua et al. (2001), Seth andTripathi (2005). The questionnaire has three sections: 1) General information about the plant; 2) Extent of practicing the principles of TQM; 3) the operational performance of the firm. Where necessary, 5-point Likert scale is applied.

The data gathered under the survey is analyzed and interpreted using correlation analysis and multiple regression analysis. Correlation analysis is used to explore the strength and direction of the linear relationship between the seven CSFs of TQM (independent variables) and the four operational performance measures (dependent variables).

Multiple Regression analysis is used to examine the relationship between TQM practices and operational performance of the Ethiopian pharmaceutical manufacturing firms and to know the effect and magnitude of TQM practices on operational performance of the firms. This is carried out by developing regression models. In each regression model, the seven quality measurement scales are considered independent variables, and each of the four operational performance measures are considered dependent variable. 


\section{DATA ANALYSIS \& INTERPRETATION}

\subsection{Back Ground Information of the Surveyed Companies \& Respondents}

A total number of 65 questionnaires were distributed to the pharmaceutical firms, which are engaged in the manufacture of medicines in Ethiopia. According to the information obtained from the Food, Beverages and Pharmaceutical Development Institute of the Ministry of Industry of Ethiopia, there are currently about 13 pharmaceutical companies which are actively engaged in the production of pharmaceutical products (medicines). Out of the total questionnaires distributed, 8 questionnaires (three are incomplete and five are un-responded) were rejected and so, the response rate comes to $87.7 \%$. The response rate is quite reasonable to reflect the views of the Ethiopian pharmaceutical manufacturing industry.

An examination of the length of standing of the firms in the industry is significant for the study as it can facilitate and substantiate the results from correlation and regression analyses. The data indicates that 10 companies (76.9\%) have been in existence for more than 10 years, 1 company $(7.7 \%)$ has been in existence for 5-10 years while 2 companies (15.4\%) have operated for a period of less than 5 years. On the other hand, taking a measure of strength of employment in these firms enable one to judge the levels of investment in TQM initiative (Fuziand Gibson, 2013). With regard to number of employees, it is found that 5 companies (38.5\%) have 200 and above employees, 6 companies (46.1\%) have 75-200 employees, while 2 companies (15.4\%) have fewer than 75 employees. The above results indicate that most of the firms in this study have been in operation for considerable period of time enough to implement TQM and have enough number of employees to practice Total Quality Management. As regards the company ownership pattern, the survey finds that $38.5 \%$ of the companies are owned by Ethiopians; $38.5 \%$ are joint ventures with collaboration between Ethiopians and foreigners and the remaining $23 \%$ are fully owned by foreigners.

The survey also finds that a $76.9 \%$ of the population had local or international quality certification; the rest don't have any certificate so far. Nearly $85 \%$ of the companies expressed their intention to obtain quality certificates on short term basis, while $15 \%$ of companies showed no interest.

The majority of individuals who participated in this research have positions in their respective companies as plant technical managers, quality assurance managers, quality control managers and production managers (84.2\%) with a minimum educational qualification of bachelor's degree. Most of the respondents had work experience in their current positions for more than 5 years $(75.4 \%)$. This indicates that the respondents have better knowledge about their respective companies.

\subsection{Descriptive Statistics of VariablesUnder Consideration}

The mean and standard deviation of the TQM constructs identified in this study are analyzed using SPSS V 25 software. Analysis of summary mean scores indicates that the overall mean score ranges from 3.46 to 3.95 with minimum standard deviation of 0.32129 and maximum standard deviation of 0.47873 for all variables in the study. The mean results are a bit higher than those of similar studies done by Haile and Raju (2016), who found a mean rate of 2.97 to 3.32 on six TQM success factors in Ethiopian manufacturing Industry. Among the seven TQM elements, supplier quality management scored the highest response mean rating of 3.95 with standard deviation being 0.32129 followed by Process Management with mean value of 3.80 and standard deviation value being 0.43016 . It is implied from the result that, the respondents believe that product design is the least TQM element practiced in the industry with a minimum overall mean rating of 3.46 with standard deviation of 0.36226 .

Similarly analysis of the mean of operational performance measures shows that flexibility performance scored the highest mean rating of 3.79 with Standard deviation of 0.47873 and cost performance showed the relatively least mean with 3.51 and standard deviation of 0.39519 .

According to Lai and Cheng (2002), a company achieving a level of quality management implementation above the mean value of 3 is regarded as having "positive" level of implementation. Whereas a company with a level of quality management implementation below the mean value of 3 would indicate that it lacks the efforts to practice quality management or to implement quality management systems. The fact that the overall mean rating of all the TQM constructs is above the midpoint on the Likert scale indicates that the majority of respondents believe that TQM practices are being implemented in the surveyed pharmaceutical firms to some extent. It is not surprising that supplier quality management and process management practices got the highest responses as pharmaceutical firms are highly involved in these activities to maintain their quality of products. The results are in agreement with the findings of Fuzi and Gibson (2013) who studied the effect of TQM implementation in Libyan firms.

\subsection{Testing significance of Means (T-test) Results}

Following the descriptive analysis, the researchers find it to be useful to examine further the extent of TQM implementation among the pharmaceutical manufacturing firms in Ethiopia. For the sake of this study, the researchers divided surveyed companies in to two categories on the basis of the number of workers. Those employing more than 200 workers are considered to be relatively larger companies and those employing below 200 workers are 
considered to be Medium and Small companies. Based on this standard, the large scale companies are five in number and the small and medium ones are eight in number.

Another test performed is to see whether there are any significant differences on the extent of TQM practices between the set of companies which have Quality award certificates and the other set of companies which don't have the certificates.

T-test results indicate that all the TQM variables are not statically significant at $p<0.05$ level, which means that there is no significant difference between the means of large companies and those of Smalland medium companies at 0.05 significance level. Despite the expectation that large companies perform better on TQM parameters than small and medium companies on grounds that they own larger resources and more advanced technologies, there is no difference on the levels of implementation of TQM between the two groups. This result supports the findings of previous studies of Hailu and Raju (2016) and Fuzi and Gibson (2013) who investigated that there was no difference on TQM implementation between large and small companies in Ethiopia and Libya respectively.

T-test was also performed to find out whether there is significant difference between those companies which have got quality certificate and those which have not. The results show that TQM variables are not statistically significant at $p<0.05$ significance level indicating there is no difference on TQM implementation between certified andnon-certified Ethiopian pharmaceutical manufacturing companies. This result is inconsistent with studies of Fuziand Gibson (2013) and Hassan and Kerr (2003). The possible explanation could be that the pharmaceutical manufacturing companies in Ethiopia already recognized the importance of TQM and implementing it to some extent regardless of their sizes or operational objectives they set. The fact that pharmaceutical industry is one of the highly regulated industries, with many rules and regulations enforced by the government to protect the health and wellbeing of the public, could also be another reason and companies are expected to follow certain quality standards such as GMP (Good Manufacturing practice).

\subsection{Correlation Analysis}

Correlation analysis was conducted in this study to explore the strength and direction of the linear relationship the seven TQM factors (independent variables) on the one side and the four operational performance measures (dependent variables) on the other side. The bivariate correlation coefficients among the TQM factors range from 0.333 to 0.768 . These results are similar to the findings of Haileand Raju (2016) with a correlation result that ranges from 0.266 to 0.796 and that of Hassan et al. (2012) which ranges from 0.216 to 0.829 .

The significant correlation among the measurement scales proves the assumption that Total
Quality Management activities strongly support and depend on one another. The highest correlation is observed to exist between process management and people management $(\mathrm{r}=.768)$; this is expected since a process oriented company requires high involvement of qualified staff to achieve the required process improvements. The second highest correlation is found to exist between customer focus and product design $(\mathrm{r}=.716)$; this is also anticipated as customer oriented companies pay a greater attention to the product development aspects to increase quality of their products. This is evident especially in pharmaceutical industry.

There is a strong positive relationship between individual TQM elements and each operational performance measures at $\mathrm{p}<0.01$ for most of the variables. The correlation coefficients between the TQM practices and performance measures range from 0.423 to 0.780 . All TQM variables are significantly and positively correlated with all performance measures. Highest correlation is observed to exist between Customer Focus and Cost Performance $(\mathrm{r}=.780)$ followed by Product Design and Quality Performance $(\mathrm{r}=.763)$. The above correlation results are in agreement with the previous studies such as Salaheldin (2009), Hassan et al. (2012), Demirbag et al. (2006) andMusran (2011) and several others who indicated that there is strong relationship between TQM factors and operational performance.

\subsection{Regression Analysis}

The purpose of this study is to analyze how the independent variables are related to the dependent variables (operational performance measures). The results of correlation analyses indicate the existence of the relationship among the variables, but do not identify the most crucial variable under this relationship. To achieve this objective, multiple regression analyses are conducted to analyze the combined effect of predictor variables (independent) on dependent variables and to test the research model and to predict operational performance measures from the TQM constructs identified in this study. The researchers used the statistical package for social sciences (SPSS $\vee 25$ ) to code, enter and compute the measurements of the multiple regression analysis for the study. Before the carrying out regression analysis, the general statistical assumptions had been checked up.

Regression analysis of TQM factors and Quality performance found out that the proposed model is statistically significant at $\mathrm{p}<0.05$ level. The independent variables account for $76.1 \%$ of the variation in Quality performance of the industry. Among the individual parameters, process management $(\beta=0.457)$, Product design $(\beta=0.45)$ and customer focus $(\beta=.361)$ are the predominant factors that are statistically significant at $\mathrm{p}<$ 0.05 level.

Regression analyses of TQM factors and Cost performance indicate that, with regression coefficient of 
$\mathrm{r}=.881$ and coefficient of determination being $\mathrm{R}^{2}=0.776$, a strong and positive relationship is inferred to exist between independent variables and dependent variable. The independent variables account for $77.6 \%$ of the variation in cost performance of the surveyed companies. Among the variables, customer focus (with $\beta=0.386$ ), process management (with $\beta=0.366$ ) and product design (with $\beta$ $=0.328)$ are statistically significant at $\mathrm{p}<0.05$.

Regression analyses of TQM factors and Delivery performance indicate that the proposed model significantly predicts the dependent variable (Delivery performance). The $\mathrm{R}^{2}$ value $(0.572)$ indicates that the independent variables together account for $57.2 \%$ of the variance in delivery performance (dependent variable). Further analyses of the individual parameters indicate that the significant contribution of the variation comes from customer focus (with $\beta=.495$ ) and People Management (with $\beta=0.386$ ).

Similarly the regression analyses of TQM factors $\&$ Flexibility to volume performance show that the model is found to be significant at $\mathrm{p}<0.05$ level to predict the dependent variable (Flexibility to volume performance). The $\mathrm{R}^{2}$ value (being 0.697) suggests that the TQM success factors together account for $69.7 \%$ of the variance in Flexibility to volume performance. The analyses of the individual parameters of the model indicate values as: customer focus $-\beta=.661$; process management $-\beta=0.436$, which are significantly impact the flexibility-to-volume performance of the companies considered.

\subsection{Verification of Hypotheses}

The results of the analyses support all the four null hypotheses.

\section{CONCLUSION}

This paper investigates the relationship and impact that Total Quality Management practices have on common important measures of operational performances (i.e. quality, cost, delivery and flexibility) with respect to Ethiopian Pharmaceutical manufacturing companies. The study employs correlation and regression analyses to justify the findings. The outcomes of correlation analysis support the hypothesis that there is positive relationship between TQM practices and operational performance of the pharmaceutical companies. The findings of regression analysis indicate that Process Management, Product Design and Customer Focus are significant factors that influence the Quality and Cost performance of the surveyed pharmaceutical companies. It is observed that Customer Focus and People Management are the most important factors that have impact on Delivery performance, whereas Process Management and Customer Focus are the most TQM success factors that account for variation in Flexibility to volume performance of the surveyed companies. TQM can significantly improve the operational performance of Pharmaceutical manufacturing companies in Ethiopia. The TQM practices that seem to play a major role in enhancing operational performance are found to be Customer Focus, Process Management, Product Design and People management. Top Management support, supplier quality management and continuous improvement do not appear to contribute to higher performance in the case of Ethiopian pharmaceutical industry. As these three factors are positively and significantly correlated with each of the performance measures and with other TQM elements, it can be argued that they impact operational performance indirectly.

Customer focus is found to be the one which contributes to the highest impact on improvement in all the four individual performance measures. This study confirms that operational performance of the pharmaceutical industry is highly dependent on the customer-focused activities of the companies. It is also identified that pharmaceutical industry should concentrate on process improvement and new product development activities to improve their operational performance. Pharmaceutical manufacturing companies should fare better than their competitors by responding rapidly to their customers' demands, manufacturing products that satisfy or exceed the expectations of their customers and anticipating future needs of their customers.

This study supports the importance and impact of TQM practices on performance of organizations as discussed in academic literature and other empirical researches. The findings suggest that effective TQM initiatives can significantly contribute towards operational performance improvements to compete in the highly dynamic business environment.

The pharmaceutical products require a strong quality focus, efficient production and best customer service. The study indicates that TQM can play a significant role on operational performance of the pharmaceutical industry in terms of improving quality of products, minimizing production costs, improving delivery and volume flexibility performances. This study offers pharmaceutical companies and their managers a better understanding of the relationship and impact that some of TQM elements have on the performance of their operations. Thus managers will get an opportunity to take better and more effective decisions about the implementation of TQM. This study can also guide organizations to prioritize the implementation of TQM based on the strategic importance of performance measures needed by the companies. In order to get better results the pharmaceutical industries should make a balance among TQM practices andadhering with Good Manufacturing Practices (GMP). GMP is giving more attention to quality and safety of the product than cost minimization and efficiency of the operations. It is 
advisable to consider all aspects of TQM practices in an organization. As this study establishes, each TQM construct improves different aspect of the operational performance of the firm.

This study has some limitations that should be addressed under future researches. The study used crosssectional data to test the research model based on the perception of respondents at a point in time. TQM activities and operational performance measures are dynamic in nature that can be affected through changes of time and as a result cross-sectional data may not address this issue.

Due to time constraint, only pharmaceutical companies which are engaged in the production of medicine are included in the study. Other similar industries such as food, medical device and supplies manufacturers are not part of the survey. The present study measures performance by the perception of managers in each company. For future research, it is better to use both objective and subjective performance measures to avoid risk of receiving biased responses. It is also recommend that future researches consider longitudinal studies to investigate the effect of TQM elements across certain period of time.

\section{REFERENCES}

[1] Anderson J.C., Rungtusanatham M., \& Schroeder R.G. (1994). A theory of quality management underlying the deming management method. Academy of Management Review, 19(3), 472-509.

[2] AU-UNIDO. (2012). African union, "Manufacturing plan for Africa: Business plan”, Addis Ababa. available at: http://www.unido.org /file admin/user_media_upgrade /Resources/Publications/Pharmaceuticals/PMPA_Business_ Plan_Nov 2012_ebook.PDF.

[3] UNCTAD: Biadgleng, E. Groot, A. \& Schellekens, O. (2011). Local production of pharmaceuticals and related technology transfer in developing countries: A case study on Ethiopia. Available at:

https://unctad.org/en/pages/PublicationWebflyer.aspx?publi cationid $=230$.

[4] Boyer, K. K. \& Pagell M. (2000). Measurement issues in empirical research: improving measures of operations strategy and advanced manufacturing technology. Journal of Operations Management, 18(3), 361-374.

[5] Brah, S. \& Lim, H. (2006). The effects of technology and TQM on the performance of logistics companies. International Journal of Physical Distribution \& Logistics Management, 36(3), 192-209.

[6] Cua, K. O., McKone, K. E., \& Schroeder, R. G. (2001). Relationship between implementation of TQM, JIT, and TPM and manufacturing performance. Journal of Operations Management, 19, 675-694.
[7] Demirbag Mehmet, Tatoglu Ekrem, Tekinkus Mehmet, \& Zaim Selim. (2006). An analysis of the relationship between TQM implementation and organizational performance Evidence from Turkish SME. Journal of Manufacturing Technology Management, 17(6), 829-847.

[8] Flynn, B., Sakakibara, S., \& Schroeder, R. (1995). Relationship between JIT and TQM: practices and performances. Academy of Management Journal, 38(5), 1325-1360.

[9] Fuzi Meftah Abusa \& Peter Gibson. (2013). Experiences of TQM elements on organizational performance and future opportunities for a developing country. International Journal of Quality \& Reliability Management, 30(9), 920-941.

[10] Haile Yeshanew Baye \& Raju R. Satya. (2016). The extent of TQM practices in Ethiopian manufacturing firms: An empirical evaluation. International Journal of Applied Research, 2(5), 238-244.

[11] Hasan M. \& Kerr R.M. (2003). The relationship between total quality management practices and organizational performance in service organizations. The TQM Magazine, 15(4), 286-291.

[12] Hassan Masood, Mukhtar Aamna, Ullah Saif Qureshi, \& Sidra Sharif. (2012). Impact of TQM Practices on firm's performance of Pakistan's manufacturing organizations. International Journal of Academic Research in Business and Social Sciences, 2(10), 232-259.

[13] Kumar Virender, Jasbir Singh, Davinder Kumar, \& Mamta Antil. (2016). Total quality management. National Journal of Advanced Research, 2(3), 05-08.

[14] Lai kee-hang. (2002). The state of quality management implementation: A cross-sectional study of quality-oriented companies in Hong Kong. Available at: https://pdfs.semanticscholar.org/fcbc/e04dddff8ef00ce2f3c5 3e3b89304b4d64ce.pdf.

[15] Lakhal L. (2009). Impact of quality on competitive advantage and organizational performance. The Journal of the Operational Research Society, 60(5), 637-645.

[16] Martínez-Lorente, Dewhurst Angel R., Dale Frank \& Barrie G. Dale. (1998). Total quality management: Origins and evolution of the term. Available at: https://www.emerald.com/insight/content/doi/10.1108/0954 4789810231261/full/html.

[17] Munizu Musran. (2011). Critical total quality management in manufacturing companies: A case study in Makassar. Journal of Economics, Business and Accountancy Ventura, 14(2), 175-184.

[18] United Nations Conference on Trade and Development (UNCTAD). (2017). The role of the services economy and trade in structural transformation and inclusive development. Available at:

https://unctad.org/meetings/en/SessionalDocuments/c1mem 4d14_en.pdf. 
[19] Oakland, J. (2003). Total quality management -Text with cases. $\left(3^{\text {rd }}\right.$ ed.). Butterworth Heinemann.

[20] Patel Setuand \& Maheswari Dilip. (2016). Total quality management: The need of the hour for pharmaceutical industry. Asian Journal of Pharmaceutical Technology \& Innovation, 04(19), 71-78.

[21] Phan, A. C. \& Matsui, Y. (2006). An empirical analysis of quality management practices in Japanese manufacturing companies. Proceedings of the 11th Annual Conference of Asia Pacific Decision Sciences Institute Hong Kong, pp. 126-137.

[22] Powell Thomas C. (1995). Total quality management as competitive advantage: A review and Empirical study. Strategic Management Journal, 16, 15-37.

[23] Raja W, Bodla MA, \& Malik SA. (2011). Evaluating the effect of total quality management practices on business performance: A study of manufacturing firms of Pakistan. International Journal of Business and Social Science, 2(9), 110-117.

[24] Sadikoglu Esin \& Olcay Hilal. (2014). The effects of total quality management practices on performance and the reasons of and the barriers to TQM practices in Turkey. Hindawi Publishing Corporation Advances in Decision Sciences, 2014, Article ID 537605, 17.

[25] Salaheldin Ismail Salaheldin. (2009), Critical success factors for TQM implementation and their impact on performance of SMEs. International Journal of Productivity and Performance Management, 58(3), 215237.

[26] Seth, D., \& Tripathi, D. (2005). Relationship between TQM and TPM implementation factors and business performance of manufacturing industry in Indian context. International Journal of Quality \& Reliability Management, 22(3), 256-277.

[27] Sila Ismail \& Ebrahimpour Maling. (2005). Critical linkages among TQM factors and business results. International Journal of Operations \& Production Management, 25(11), 1123-1155.

[28] Slack Nigel, Brandon Alistair, \& Johnston Robert. (2013). Operation management. ( $7^{\text {th }}$ ed.), Pearson Publishing.

[29] WHO. (2011). Local production and access to medicines in low- and middle-income countries: A literature review and critical analysis. Available at: http://www.who.int/phi/en/

[30] World Trade Organization (WTO). (2017). Report to the TPRB from the Director-General on trade-related developments. Available at: https://docs.wto.org/dol2fe/Pages/SS/directdoc.aspx?filena $\mathrm{me}=\mathrm{q}: / \mathrm{WT} / \mathrm{TPR} / \mathrm{OVW} 11 . \mathrm{pdf}$ 